\title{
Copper chelation selectively kills colon cancer cells through redox cycling and generation of reactive oxygen species
}

\author{
Maamoun Fatfat ${ }^{1}$, Raghida Abou Merhi², Omar Rahal ${ }^{1}$, Detcho A Stoyanovsky ${ }^{3}$, Angela Zaki ${ }^{1}$, Hazar Haidar ${ }^{1}$,
} Valerian E Kagan ${ }^{3}$, Hala Gali-Muhtasib ${ }^{1^{*}}$ and Khaled Machaca ${ }^{4^{*}}$

\begin{abstract}
Background: Metals including iron, copper and zinc are essential for physiological processes yet can be toxic at high concentrations. However the role of these metals in the progression of cancer is not well defined. Here we study the anti-tumor activity of the metal chelator, TPEN, and define its mechanism of action.

Methods: Multiple approaches were employed, including cell viability, cell cycle analysis, multiple measurements of apoptosis, and mitochondrial function. In addition we measured cellular metal contents and employed EPR to record redox cycling of TPEN-metal complexes. Mouse xenografts were also performed to test the efficacy of TPEN in vivo.

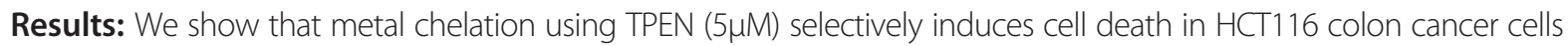
without affecting the viability of non-cancerous colon or intestinal cells. Cell death was associated with increased levels of reactive oxygen species (ROS) and was inhibited by antioxidants and by prior chelation of copper. Interestingly, HCT116 cells accumulate copper to 7-folds higher levels than normal colon cells, and the TPEN-copper complex engages in redox cycling to generate hydroxyl radicals. Consistently, TPEN exhibits robust anti-tumor activity in vivo in colon cancer mouse xenografts.
\end{abstract}

Conclusion: Our data show that TPEN induces cell death by chelating copper to produce TPEN-copper complexes that engage in redox cycling to selectively eliminate colon cancer cells.

Keywords: Colon cancer, Metal chelation, TPEN, Redox cycling, Copper, Reactive oxygen species

\section{Background}

Cancer is one of the leading causes of mortality and represents a tremendous burden on patients and societies. Colorectal cancers are associated with one of the highest morbidity and mortality rates in both men and women (Globocan 2008, IARC 2010). Although the etiology of cancer varies greatly between different types of neoplasms, a hallmark finding is a defect in cell cycle regulation [1,2]. Such cell cycle disruption is associated with genomic instability, due to mutations and chromosomal aberrations that disrupt critical housekeeping

\footnotetext{
* Correspondence: amro@aub.edu.lb; khm2002@qatar-med.cornell.edu 'Department of Biology, American University of Beirut, Beirut, Lebanon ${ }^{4}$ Department of Physiology and Biophysics, Weill Cornell Medical College, Doha, Qatar

Full list of author information is available at the end of the article
}

functions, including DNA repair and cell cycle checkpoints. Because these homeostatic mechanisms are essential for both normal and cancerous cells, treatments targeted at selectively destroying cancer cells become challenging.

The G2-M transition marks the entry of cells into the division phase of the cell cycle. Interestingly, metal chelation using the acyclic amino metal chelator $N$, $N, N, N^{p}$-tetrakis-[2-pyridylmethyl]-ethylenediamine (TPEN) prevents frog oocytes from entering meiosis [3]. TPEN, an uncharged polydentate ligand with nitrogens as donor atoms, has remarkably high affinity for a broad spectrum of metal ions, including copper, iron and zinc [4]. TPEN-induced meiotic arrest is due to the lack of activation of $\mathrm{Cdc} 25 \mathrm{C}$, a dual specificity phosphatase in oocytes that represents the rate limiting step in activating the master regulator of the G2-M transition 
cyclin-dependent kinase 1 (Cdk1) [5]. This is because Cdc25C is a $\mathrm{Zn}^{2+}$-binding protein and removal of $\mathrm{Zn}^{2+}$ inhibits its ability to interact with and dephosphorylate Cdk1 [3]. TPEN treatment also results in meiosis arrest in mouse oocytes [6].

TPEN-dependent metal chelation has noticeably distinct effects during the mitotic cell cycle as compared to meiosis. TPEN induces apoptosis in different cell types, including lymphocytes and splenocytes [7,8], epithelial cells [9], hepatocytes [10], breast cancer [11], HT-29 colorectal cancer [12], ovarian cancer [13], pancreatic cancer [14], and prostate cancer [15]. However the mechanisms of actions proposed for the TPEN-dependent cell killing are quite varied: TPEN was proposed to decrease the levels of the apoptosis inhibitor XIAP due to $\mathrm{Zn}^{2+}$ chelation [15]. $\mathrm{Zn}^{2+}$ depletion has also been implicated in mitochondrial injury, activation of caspases (primarily caspase 3 ) and apoptosis $[8,9,14]$. Furthermore, TPEN treatment results in depletion of glutathione causing increased redox stress [10]. Collectively these findings argue that TPEN induces cell killing through varied mechanisms, which may be expected given the diverse roles that metals chelated by TPEN play in physiological processes. Indeed TPEN has been used as a selective $\mathrm{Zn}^{2+}$ chelator despite the fact that it has a significantly higher affinity for $\mathrm{Cu}^{2+}$ (Stability constant for $\mathrm{Zn} 15.5$ and for $\mathrm{Cu}$ 20.5) [16]. There is evidence at least in the hippocampus that TPEN in vivo chelates $\mathrm{Zn}^{2+}$ with better efficiency as compared to $\mathrm{Cu}^{2+}$ [17].

Metal homeostasis is important for biological function and needs to be tightly regulated since either metal deficiencies or metal excesses tend to be toxic. Metals have played important roles in cancer treatment since ancient times with the use of arsenic trioxide to treat different cancers including leukemia in the $18^{\text {th }}$ and $19^{\text {th }}$ century [18]. More recently platinum based compounds such as cysplatin and carboplatin have become the chemotherapeutic agents of choice for many cancers [19]. Interestingly cancer cells are addicted to high iron levels and accumulate the metal through transferrindependent uptake [20,21]. Furthermore cancer cells concentrate high levels of copper, which is presumed to be important for both angiogenesis and metastasis [22]. Therefore, transition metals are likely to play important roles in the development and growth and neoplasms.

Here we show that TPEN-mediated metal chelation results in selective killing of HCT116 colon cancer cells without affecting normal cells. TPEN cytotoxicity is due to the generation of ROS as it is reversed by antioxidants. Interestingly, HCT116 colon cancer cells accumulate 7-fold higher levels of copper compared to normal cells. The TPEN-copper complex undergoes redox cycling reactions. These results suggest that TPEN chelates accumulated copper in HCT116 cells making it available for redox cycling leading to cell toxicity and death. We further show that TPEN effectively inhibits colon cancer tumor growth in human colon cancer xenografts in mice. Therefore metal chelation provides a promising selective approach to target colon cancer.

\section{Methods}

\section{Cell culture}

Human colorectal cancer cells, SW480, HT-29 and LOVO were kindly provided by the American Type Culture Collection (ATCC). Cells were cultured in RPMI 1640 (Sigma-Aldrich, UK) with 20mM HEPES and L-Glutamine at $37^{\circ} \mathrm{C}$ in a humidified atmosphere of $5 \% \mathrm{CO} 2$ and $95 \%$ air. Media was supplemented with $1 \%$ Penicillin-Streptomycin $(100 \mathrm{U} / \mathrm{ml})$ and $10 \%$ heat-inactivated FBS (Sigma-Aldrich, Germany). Unless otherwise mentioned, cells were seeded at $1.2 \times 105$ cells $/ \mathrm{ml}$ and treated with TPEN (Sigma-Aldrich) at 50\% confluence. TPEN was prepared in DMSO and the final DMSO concentration used on cells $<0.3 \%$.

\section{Cell viability assays $\&$ antibodies}

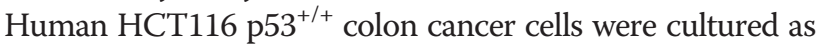
previously described [23]. Cell viability was measured using the MTT-based Cell Titer 96 non-radioactive cell proliferation kit (Promega Corp, Madison, Wisconsin, USA). Cell cycle analyses were performed on propidium iodide stained cells using flow cytometry (Becton Dickinson, Research Triangle, NC). The TUNEL assay used the In Situ Cell Death Detection Kit according to the manufacture instructions (Roche Diagnostics Corporation, Mannheim, Germany). For Annexin V staining cells were incubated in Annexin-V-Fluos labeling solution [20 $\mu \mathrm{l}$ Annexin reagent and $20 \mu \mathrm{l} \mathrm{PI}(50 \mu \mathrm{g} / \mathrm{ml})$ in $1000 \mu \mathrm{l}$ incubation buffer $\mathrm{pH}$ 7.4 (10 mM Hepes/ $\mathrm{NaOH}, 140 \mathrm{mM} \mathrm{NaCl}, 5 \mathrm{mM} \mathrm{CaCl} 2)$, then analyzed by flow cytometry. Caspase 3, 8 and 9 activities were assessed using Colorimetric Assay kits according to manufacturer insutructions ( $R$ \& $D$ Systems-BF4100). Primary antibody used for Western blots: XIAP \#2042S; Caspase 3 \#9665S; Caspase 9 \#9502S; Bax \#2772; PARP \#9542S, from Cell Signaling. Cytochrome C sc-13560 from Santa-Cruz and GAPDH \#5476 from Abnova.

\section{DCFH assay}

Cells were treated with TPEN for 10, 20, 30 and $45 \mathrm{~min}$. In experiments which involved addition of the antioxidant $\mathrm{N}$-acetyl-L-cysteine (NAC), cells were treated with $5 \mathrm{mM}$ NAC for $2 \mathrm{~h}$ before TPEN after which $10 \mu \mathrm{M}$ of the CM-H2DCFDA dye was added for $20 \mathrm{~min}$. Cells were washed, harvested by centrifugation and the pellet washed and re-suspended in $500 \mu \mathrm{l}$ PBS followed by flow cytometery. 


\section{Mitochondrial membrane potential}

Cells were washed, pelleted and incubated in $500 \mu \mathrm{l}$ of rhodamine buffer [ $5 \mu \mathrm{m}$ rhodamine $123,130 \mathrm{mM} \mathrm{NaCl}$, $5 \mathrm{mM} \mathrm{KCl}, 1 \mathrm{mM} \mathrm{Na} 2 \mathrm{HPO}_{4}, 1 \mathrm{mM} \mathrm{CaCl}, 1 \mathrm{mM} \mathrm{CaCl}_{2}$, $1 \mathrm{mM} \mathrm{MgCl}_{2}$, and $25 \mathrm{mM}$ Hepes (pH7.4)] for $30 \mathrm{~min}$ at $37^{\circ} \mathrm{C}$, then analyzed by flow cytometry.

\section{Atomic absorption}

$10^{6}$ HCT116 and NCM460 cells were collected in $8 \mathrm{ml}$ $\mathrm{HNO}_{3} 65 \%+2 \mathrm{ml} \mathrm{H}_{2} \mathrm{O}_{2} 30 \%$ and digested in a closed vessel microwave (Milestone ETHOS PLUS with HPR-1000/10S high pressure rotor). Cell lysates were measured for ion concentration against standard solutions prepared for Copper, Zinc and Iron in deionized water in an atomic absorption spectrophotometer (Furnace).

\section{UV/VIS and EPR spectroscopy}

EPR spin-trapping experiments were carried out with a JEOL-RE1X spectrometer (Kyoto, Japan). Spectrometer settings were as follows: field center, $335.094 \mathrm{mT}$; microwave power, $10 \mathrm{~mW}$; sweep time, $2.0 \mathrm{~min}$; time constant, $0.3 \mathrm{~s}$; and modulation width, $0.2 \mathrm{mT}$ ). UV/VIS spectra were recorded with Helios Alpha spectrophotometer (Thermo Fisher Scientific, Inc.; Pittsburgh, PA). All measurements were performed at room temperature.

\section{Mouse xenografts}

NOD/SCID female mice, (6-8 weeks, 20 g) (Charles River Laboratories, France) were divided into two groups of 8 mice each and maintained in Maxi-miser hepafiltered facility. $2-3 \times 10^{6}$ HCT-116 tumor cells in $100 \mu$ of $0.9 \%$ $\mathrm{NaCl}$ were inoculated subcutaneously in the flank. An average age (6-8 weeks) and body weight of mice (18-22 g) were used for the experiments. Prior to manipulations, mice were anaesthetized with isoflurane (Forane ${ }^{\circ}$, Abbott) by inhalation. On day 7 post inoculation mice received i.p. injections of either saline (control) or $20 \mathrm{mg} / \mathrm{kg}$ TPEN every other day for 28 days. Tumor measurements were performed 3 times per week using a sterile Vernier caliper. Tumor volume was calculated by the formula: Volume $=\pi /$ 6 (length $\times$ width $\times$ height). A 5-10\% loss of body weight was detected in mice receiving TPEN treatment in comparison to the control but they otherwise looked healthy and tolerated the drug treatment well. The use of laboratory animals was in accordance with the guidelines of the Institutional Animal Care and Use Committee (IACUC). The IACUC committee at the American University of Beirut where the animal studies were conducted reviewed and approved the studies described.

\section{Immunohistochemical analysis of xenografts}

Tissue sections $(4 \mu \mathrm{m})$ were stained with and anti-Ki-67 antibody (Santa-Cruz, US), for $60 \mathrm{~min}$ followed by secondary and tertiary antibodies and incubated with the chromogen (Zymed, US) before counterstaining with Hematoxylin. To assess the extent of total cell death, tissue sections were stained by using the terminal deoxyribonucleotidyl transferase-mediated dUTP-nick-end labeling (TUNEL) assay, according to manufacturer's instructions (in situ cell death detection kit, fluorescein; Roche) and counterstained with PI. Slides were analyzed under LSCM fluorescent confocal microscope (LSM 410, Zeiss, Germany).

\section{Statistical analyses}

Data are expressed as the mean \pm standard deviation, and statistical significance between different groups was determined using a two-tailed Student's t-test. Statistical significance was defined as a ${ }^{*} \mathrm{p}<0.05$ and ${ }^{* *} \mathrm{p}<0.01$.

\section{Results}

\section{TPEN selectively kills HCT116 human colon cancer cells}

Treatment of HCT116 colon cancer cells with $5 \mu \mathrm{M}$ TPEN for $24 \mathrm{~h}$ results in a noticeable decrease in cell density (Figure 1A). In contrast, non-cancerous colon (NCM460) or intestinal (FHS74Int) cell lines (see methods for cell lines description) were resistant to TPEN at these concentrations (Figure 1A). A dose response of TPEN toxicity in the two non-cancerous (NCM460 and FHS74Int) and in four independent human colorectal cancer cell lines (HCT116, SW 480, HT-29, and LOVO), consistently revealed a significantly higher sensitivity of the cancerous cells as compared to their non-cancerous counterpart. The $\mathrm{IC}_{50}$ for the non-cancerous cells was $8.3 \mu \mathrm{M}$ and $13 \mu \mathrm{M}$ for the NCM460 and FHS74Int respectively. In contrast the $\mathrm{IC}_{50}$ for the cancerous cells were $2.7 ; 4.0 ; 4.3$ and $4.5 \mu \mathrm{M}$ for the HCT116; SW480; HT-29 and LOVO cells respectively. Importantly, selective killing of cancerous cells $(15.3 \pm 0.4 \% ; 25.07+6 \% ; 10.82+1.18 \%$; $33.35+5.22 \%$ survival for HCT, SW, LoVo, HT respectively) could be achieved at $5 \mu \mathrm{M}$ TPEN for $24 \mathrm{~h}$, concentrations at which $96.9 \pm 7.52 \%$ and $95.3 \pm 1.7 \%$ of the NCM460 and FHS74Int cell lines remained viable (Figure 1B). Flow cytometry analysis in HCT116 cells showed that TPEN toxicity is time-dependent as indicated by the gradual enrichment of the pre- $G_{1}$ percentage in the cell population (Figure 1C). No obvious cell cycle arrest was associated with the TPEN treatment (Figure 1C), indicating that the primary effect of TPEN on HCT116 cells is to induce cell death.

\section{TPEN induces apoptosis in HCT116 cells}

The observed increases in the $\mathrm{PreG}_{1}$ population are associated with higher levels of apoptosis, as indicated by TUNEL and Annexin V assays in TPEN treated cells in a dose-dependent fashion (Figure 1D). An early hallmark of most apoptotic cell death is increased mitochondrial membrane permeability. TPEN induced permeabilization 


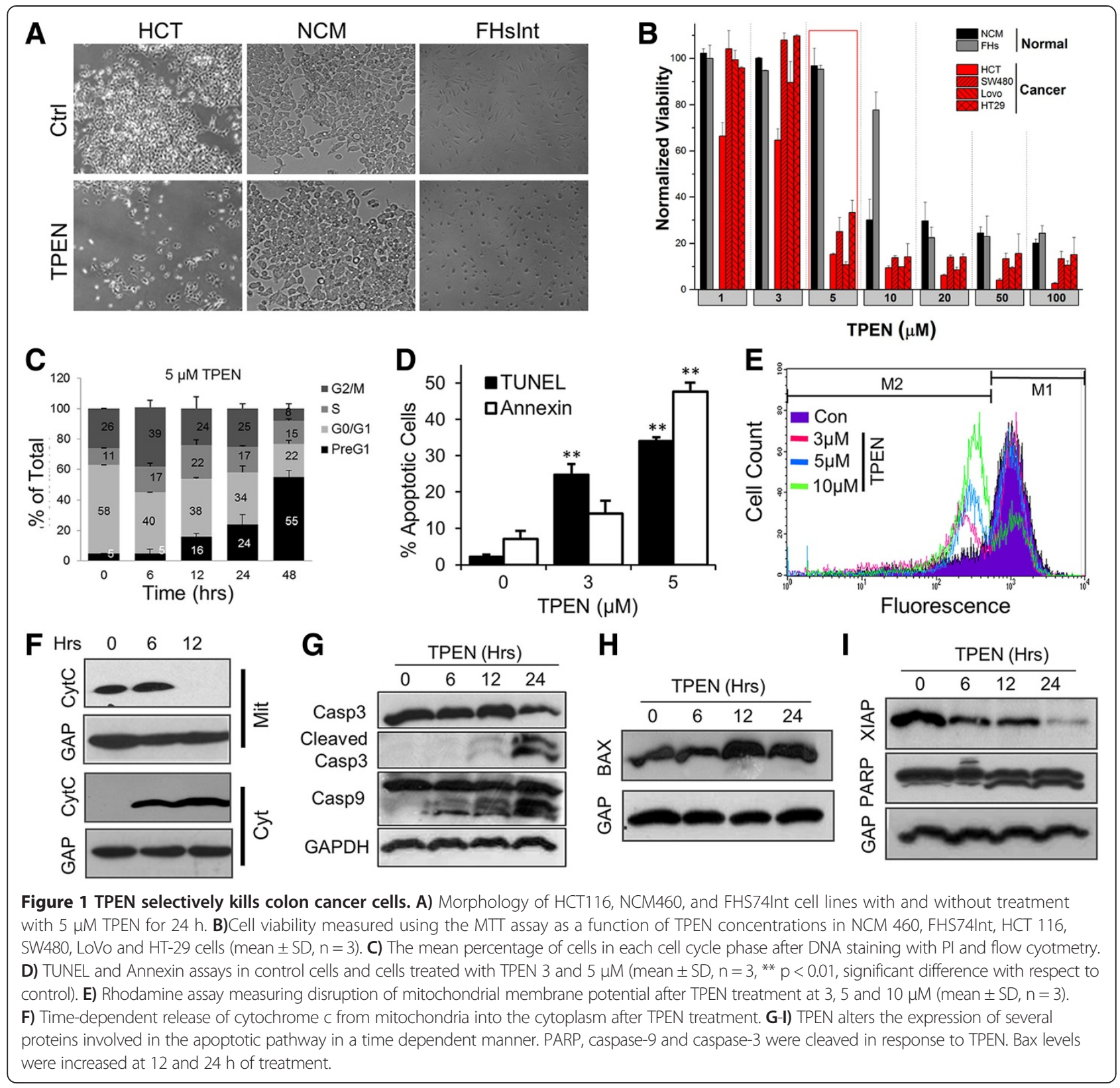

of the mitochondrial membrane, as indicated by changes in mitochondrial membrane potential $\left(\Delta \Psi_{\mathrm{m}}\right)$ (Figure 1E). Interestingly, this effect may be associated with TPEN's ability to "extract" essential metals, particularly iron and copper from mitochondrial electron carriers, thus facilitating the loss of membrane potential and the deviation of electron flow to molecular oxygen $\mathrm{O}_{2}$ to generate superoxide and $\mathrm{H}_{2} \mathrm{O}_{2}$. Treatment with TPEN induced disruption of the mitochondrial membrane potential in a dose-dependent fashion, as detected by the reduced accumulation of the fluorescent dye rhodamine (Figure 1E). Consistently, disruption of the mitochondrial membrane is associated with the release of cytochrome c from the mitochondria and its accumulation in the cytosolic fraction (Figure 1F).

These results argue that TPEN induces apoptosis in HCT116 cells through the intrinsic pathway. In agreement with this conclusion, TPEN modulated key markers of apoptosis resulting in cleavage of caspases 3 and 9 into their active products (Figure 1G), cleavage of PARP, and accumulation of the pro-apoptotic BAX, which is typically observed upstream of mitochondrial dysfunction (Figure $1 \mathrm{H}$ ). TPEN killing of cancer cells was reported to be associated with degradation of the X-linked inhibitor of apoptosis (XIAP) $[15,24]$. Consistently, treating HCT116 cells with TPEN results in XIAP degradation (Figure 2A, XIAP). XIAP 

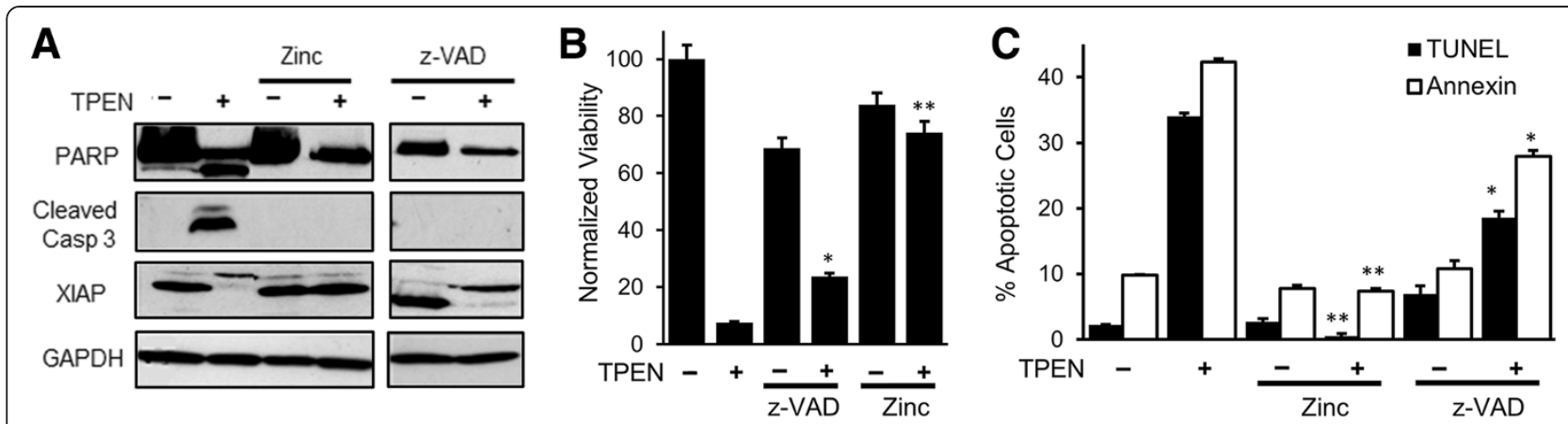

Figure 2 TPEN-dependent cell death is partially due to apoptosis induction. A) Cleavage of PARP, caspase-3 and degradation of XIAP in TPEN-treated cells was reversed by the addition of $z-V A D$-fmk or $\mathrm{ZnSO}_{4}$. B) MTT viability assay in control (-) and TPEN-treated (+) cell in the presence of either z-VAD-fmk to inhibit caspases or $\mathrm{ZnSO}_{4}($ mean $\pm \mathrm{SD}, \mathrm{n}=3$ ). C) Annexin and TUNEL assays under similar condition as in panel $\mathbf{A}$ ) (mean $\pm S D, n=3$ ). ${ }^{*} p<0.05$ and ${ }^{* *} p<0.01$, significant difference with respect to TPEN.

degradation is blocked by incubations with zinc, showing that it is dependent on TPEN's metal chelation properties (Figure 2A). However, inhibition of caspases with the pancaspase inhibitor z-VAD was ineffective in blocking XIAP degradation (Figure 2C), arguing that TPEN-dependent XIAP degradation occurs upstream of caspase activation. These data show that TPEN induces apoptosis with all the associated molecular hallmarks.

The ability of TPEN to induce death of HCT116 colon cancer cells was dependent on its metal chelation properties, as it was reversed when TPEN was added in the presence of $\mathrm{ZnSO}_{4}$ (Figure 2B, Zinc). TPEN is a metal chelator with high affinity for zinc, copper and iron. Addition of exogenous $\mathrm{Zn}^{2+}$ is expected to associate with and saturate TPEN, preventing it from chelating other metals in the cell. $\mathrm{ZnSO}_{4}$ addition effectively abrogated the toxic effects of TPEN as indicated by the cell viability assay (Figure 2B, Zinc), TUNEL and annexin staining (Figure 2C, Zinc) and PARP, caspase 3 and XIAP cleavage (Figure 2A, Zinc). In contrast, inhibition of caspases using the pan-caspase inhibitor z-VAD-fmk resulted in significant, yet only partial reversal of TPEN toxicity (Figure 2B and 2C). z-VAD treatment effectively blocked caspase 3 and PARP cleavage (Figure 2A), this however was not sufficient to fully reverse TPEN-dependent cell killing (Figure $2 \mathrm{~B}$ and $2 \mathrm{C}$, z-VAD). These results suggest that the toxic effects of TPEN are mediated only partially through the induction of apoptosis, and potentially invoke other death pathways such as necrosis and autophagy.

\section{TPEN toxicity is associated with ROS generation}

To investigate mechanisms involved in TPEN-dependent cell killing, we tested the involvement of reactive oxygen species (ROS) production using the DCFDA assay, since TPEN has been previously implicated in ROS production [25]. TPEN treatment caused a significant increase in intracellular ROS as early as $10 \mathrm{~min}$ after treatment, which gradually decreased over the next $30 \mathrm{~min}$ (Figure 3A).
This ROS increase in HCT116 was significantly higher than that observed following the addition of $250 \mu \mathrm{M}$ of $\mathrm{H}_{2} \mathrm{O}_{2}$ (Figure 3A). In contrast, TPEN-induced ROS production in the NCM460 normal colon cells was significantly smaller (Figure $3 \mathrm{~A}$ ), and decayed back to baseline with a faster time course than in HCT116 cells (Figure 3B). Similar to the data obtained in HCT116 cells, TPEN treatment of two other colon cancer cell lines, SW480 and LOVO, also resulted in the production of significantly higher levels of ROS as compared to the normal NCM colon cells (Additional file 1: Figure S1). These data show that TPEN induces a 6-7fold higher ROS in colon cancer cells as compared to the normal NCM460 cells, and that this increased ROS lasts for tens of minutes longer in HCT116 cells (Figure 3A, 3B and Additional file 1: Figure S1). Hence there is good correlation between ROS induction and TPEN toxicity in these two cell lines.

To assess whether ROS generation is involved in mediating TPEN-induced cell death, we pretreated HCT116 cells with antioxidants, including NAC and vitamin E, after which cell viability and apoptosis were assessed. As expected, the general ROS scavenger NAC and vitamin E significantly decreased $\mathrm{H}_{2} \mathrm{O}_{2-}$ and TPEN-induced ROS generation (Additional file 2: Figure S2). Antioxidants effectively prevented TPEN toxicity as measured by cell viability (Figure 3C), TUNEL and annexin assays (Figure 3D), and reversed caspase 3 and 9 activation (Additional file 3: Figure S3). This argues that TPEN-mediated cell killing requires ROS production. Furthermore, the protective effects of antioxidants are also compatible with the idea of transition metal catalyzed oxidative stress. However, the observed incomplete protection by two different antioxidants - NAC and Vit $\mathrm{E}$ - may indicate contribution of non-redox driven pathways, such as $\mathrm{Zn}$-dependent effects, given previous reports that argued for a role of Zn-homeostasis in TPEN toxicity. Nonetheless, the significant reversal of the TPEN 

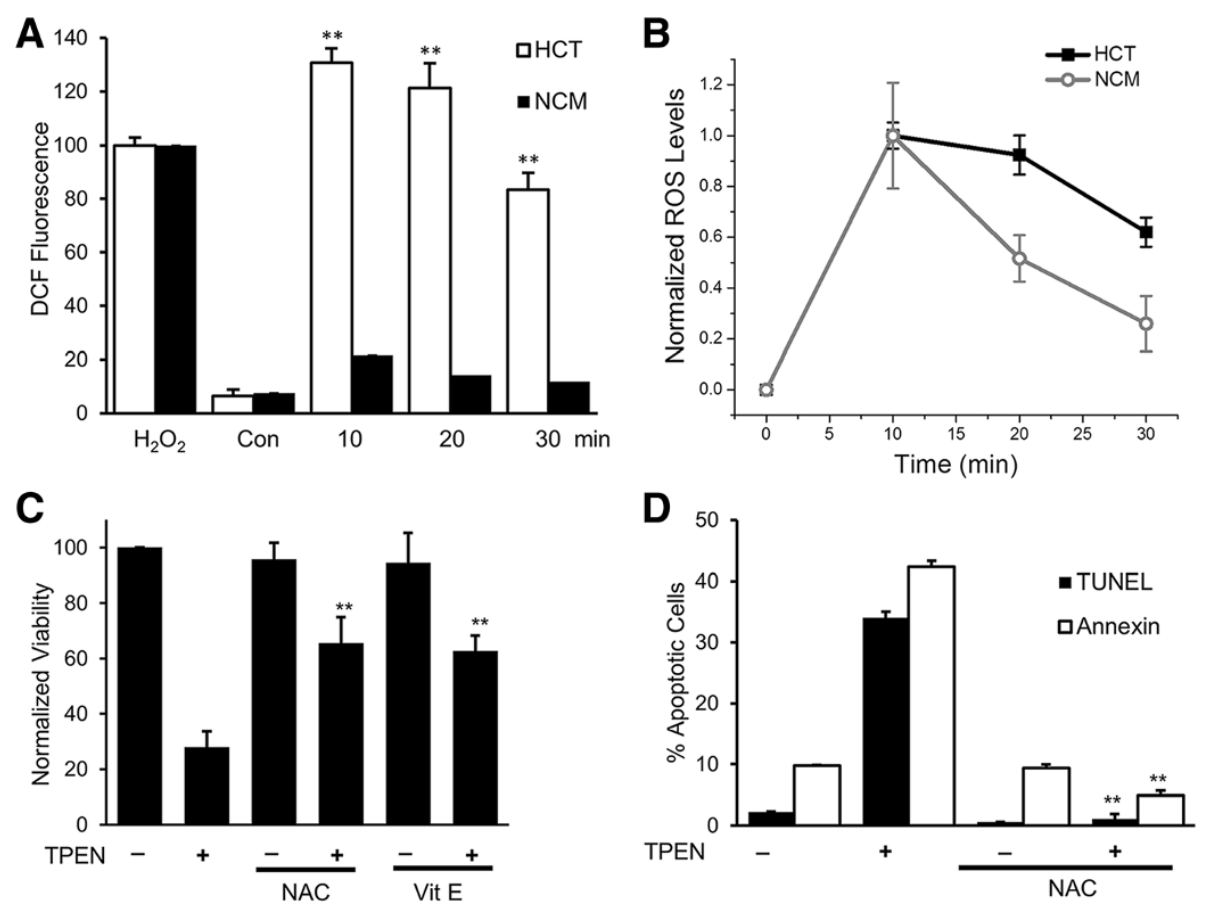

Figure 3 TPEN induces ROS generation in HCT116 cancer cells. A) Time course of TPEN-induced ROS generation in HCT116 and NCM460 cells. Control (Con) represents cells that have been treated with carrier DMSO. ROS generated in response to $250 \mu \mathrm{M} \mathrm{H}_{2} \mathrm{O}_{2}$ is also shown (mean $\pm \mathrm{SD}, \mathrm{n}=3$ ). B) Same data as in panel A) normalized to maximum levels of ROS induced in either the HCT116 or the NCM460 cells. Time zero represents carrier alone treatment and was set at zero. C) Cell viability in cells treated with TPEN in the presence or absence of the antioxidants NAC or vitamin E (mean \pm SD, $n=3)$. D) Apoptosis measured using the TUNEL and Annexin assays in cells treated with TPEN in the presence and absence of NAC $($ mean $\pm S D, n=3)$. ** $p<0.01$, significant difference with respect to TPEN in $\mathbf{C}$, and $\mathbf{D}$, and with respect to control in $\mathbf{A}$.

toxicity using two different anti-oxidants strongly argues for an essential role for ROS production in TPEN toxicity.

\section{TPEN-metal complex are redox active}

We were then interested in defining the mechanism by which TPEN induces ROS generation and cell killing. In the presence of ascorbic acid, TPEN has been shown to mobilize iron from ferritin, presumably via formation of a $\left[\right.$ TPEN-Fe $\left.e^{(I I)}\right]$ complex. This reaction may have toxicological consequences, as [TPEN-Fe ${ }^{(\mathrm{II})}$ ] can participate in Fenton-like reactions with concomitant generation of hydroxyl radical and/or high-valent iron ${ }^{\text {(IV) }}$-oxo species. In addition, TPEN was suggested to deplete intracellular copper in several cell types $[11,26,27]$. Hence, we carried out experiments to verify whether ascorbic acid can reduce $\left[\right.$ TPEN-Fe $\left.{ }^{(\mathrm{III})}\right]$ to $\left[\mathrm{TPEN}-\mathrm{Fe}^{(\mathrm{II})}\right]$, and $\left[\mathrm{TPEN}-\mathrm{Cu}^{(\mathrm{II})}\right]$ to $\left[\right.$ TPEN-Cu $\left.{ }^{(I)}\right]$. This is important in the context of the ROS observed in response to TPEN treatment because the reduced forms of these complexes may have the potential to generate hydroxyl radical in the presence of $\mathrm{H}_{2} \mathrm{O}_{2}$.

Ascorbic acid reduces [TPEN-Fe(III)] at a relatively low rate (Figure 4A, closed circles), thus setting the stage for induction of a futile redox cycle whereby [TPEN-Fe(II)] autoxidizes to [TPEN-Fe(III)] with concomitant generation of superoxide anion radical. Incubation of ascorbic acid with [TPEN-Cu(II)], however, did not result in changes in the electronic spectrum of the complex (Figure 4B). This suggests that either ascorbate does not possess the required potential to reduce [TPEN-Cu(II)] to $[\mathrm{TPEN}-\mathrm{Cu}(\mathrm{I})]$, or the latter rapidly autoxidized with generation of superoxide anion radical. To verify the latter hypothesis, we assessed the ability of [TPEN-Cu (II)] to generate hydroxyl radical in a reaction system consisting of $\mathrm{H} 2 \mathrm{O} 2$, ascorbic acid, dimethylsulfoxide (CH3SOCH3; DMSO) and N-tert-butyl-alha-phenylnitrone $(\mathrm{PBN})$ as a spin trapping agent. In the complete reaction system, the initial Electron Paramagnetic Resonance.

(EPR) doublet of the semidehydroascorbyl radical (ascorbate + radicals $\rightarrow$ semidehydroascorbyl radical) was gradually substituted by the characteristic 6-line EPR spectrum of $\mathrm{PBN} / \mathrm{CH}_{3}$ (Figure $4 \mathrm{C} ; \mathrm{CH}_{3} \mathrm{SOCH}_{3}+\mathrm{HO} \rightarrow$. $\left.\mathrm{CH}_{3}+\mathrm{CH}_{3} \mathrm{~S}(\mathrm{O}) \mathrm{OH} ; \mathrm{CH}_{3}+\mathrm{PBN} \rightarrow \mathrm{PBN} / \mathrm{CH}_{3}\right)$. The formation of $\mathrm{PBN} / \mathrm{CH}_{3}$ was inhibited by depletion of ascorbic acid, as assessed by the disappearance of the semidehydroascorbyl radical. No $\mathrm{PBN} / \mathrm{CH}_{3}$ formation was observed if either $\mathrm{H}_{2} \mathrm{O}_{2}$ or ascorbic acid was omitted from the reaction system. Under these experimental conditions, the rate of $\mathrm{PBN} / \mathrm{CH}_{3}$ formation by $\left[\mathrm{TPEN}-\mathrm{Fe}^{(\mathrm{III})}\right.$ ] was 4 times slower than that observed with [TPEN-Cu $\left.{ }^{\text {(II) }}\right]$ (Figure 4D). The results obtained indicate that both [TPEN-Fe $\left.{ }^{(\mathrm{II})}\right]$ and 


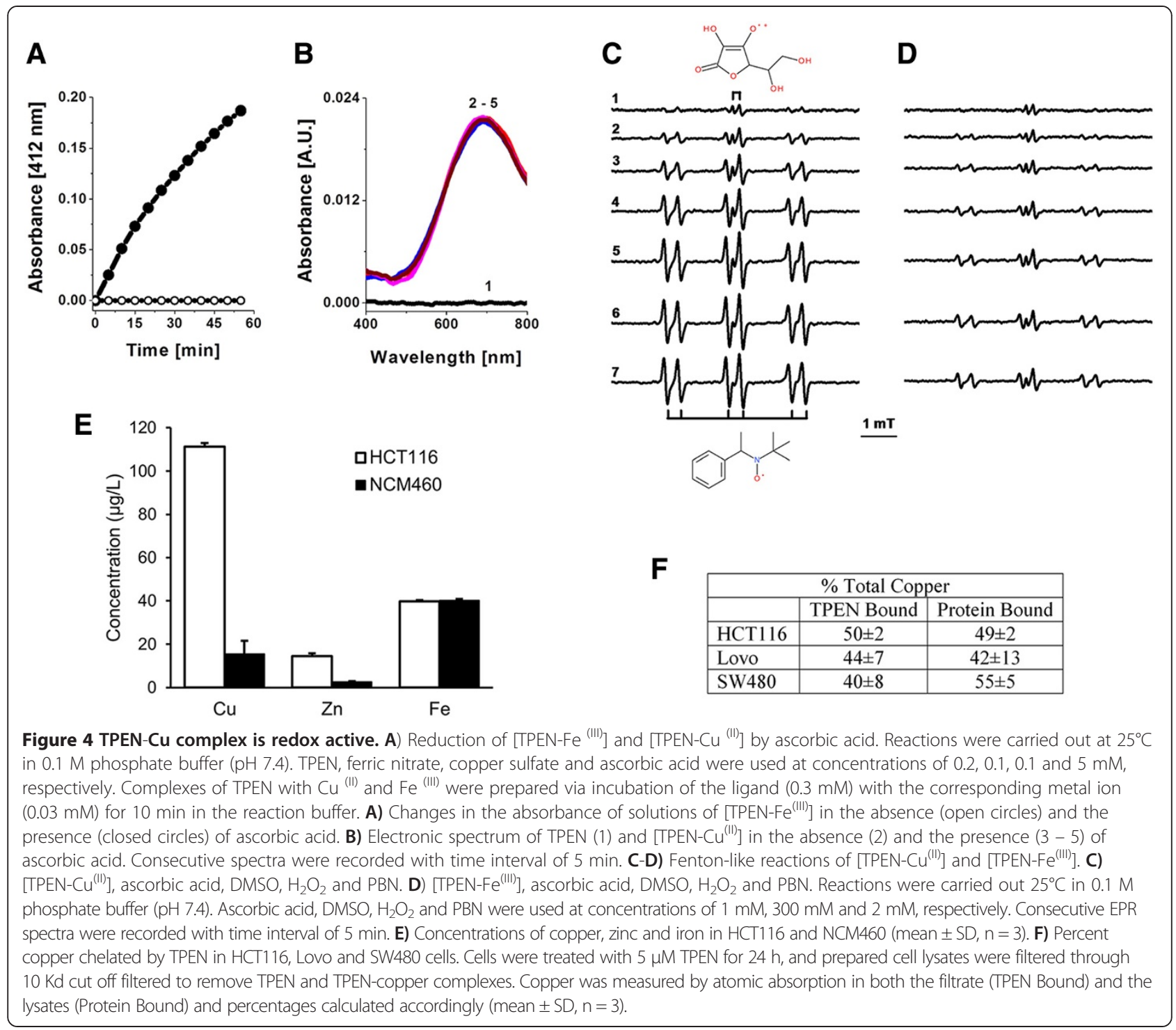

$\left[\right.$ TPEN-Cu $\left.{ }^{(\mathrm{I})}\right]$ have the potential to generate $\mathrm{HO}$ in biological systems ([TPEN-Me $\left.{ }^{(\mathrm{n}+)}\right]+\mathrm{H}_{2} \mathrm{O}_{2} \rightarrow[$ TPEN$\left.\left.\mathrm{Me}^{(\mathrm{n}+1)}\right]+\mathrm{HO}+\mathrm{HO}^{-}\right)$. These observations extend the reaction mechanism of the breakdown of $\mathrm{H}_{2} \mathrm{O}_{2}$ by ([TPEN-Fe $\left.{ }^{(\mathrm{n}+)}\right]$, which includes the formation of highvalent oxo-species that can activate $\mathrm{C}-\mathrm{H}$ bonds and epoxidate $>\mathrm{C}=\mathrm{C}<$ bonds [28-30]. Hence the TPEN-Fe and TPEN-Cu complex engage in redox cycling resulting in the generation of ROS. As such chelation of cellular copper and/or iron by TPEN has the potential to produce ROS leading to cellular toxicity.

\section{Colon cancer cells accumulate higher levels of copper} and zinc

Given the potential of TPEN-Cu ${ }^{\text {(II) }}$ and TPEN-Fe ${ }^{\text {(II) }}$ to redox-cycle in the presence of $\mathrm{H}_{2} \mathrm{O}_{2}$ and a reductant (eg, ascorbate) to yield hydroxyl radicals, the ability of these TPEN-metal complexes to produce cellular damage is likely to be proportional to the amount of chelatable metals in cells. Tumor tissues from multiple cancers have been reported to have elevated copper content [22]. This is also the case for HCT116 cells as shown by atomic absorption spectroscopy studies, where both copper (enriched $\sim 7$-folds) and zinc (enriched $\sim 5.5$-folds) accumulate to significantly higher levels as compared to NCM460 (Figure 4E). In contrast, iron content was similar between the two cell types (Figure 4E). Similar accumulation of copper and zinc but not iron were observed in two additional colon cancer cell lines, LoVo and SW480, where the measured levels for $\mathrm{Cu}$ were 120.25 and $99.56 \mu \mathrm{g} / \mathrm{L}$; $\mathrm{Zn} 20.34$ and $15.26 \mu \mathrm{g} / \mathrm{L}$; Fe 44.24 and $46.25 \mu \mathrm{g} / \mathrm{L}$ in LoVo and SW480 cells respectively. Given that zinc is not redox active and that the levels of iron are similar in both cell types, the 
mechanisms of action of TPEN is likely to involve formation of a TPEN-Cu complex that engages in redox cycling to generate ROS and cause cellular damage. Interestingly the fold enrichment of copper in HCT116 cells (Figure 4E) mirrors the fold increase in redox-cycling activity revealed by DCFH oxidation measured in these cells as compared to NCM460 following TPEN treatment (Figure 3A).

\section{Cellular copper is required for TPEN toxicity}

The above data support a model where TPEN induces selective death of cancer cells through its ability to chelate copper away from cellular proteins, resulting in the formation of a TPEN-copper complex able to engage in redox cycling thus generating ROS and inducing cell death. Interestingly, the TPEN-Cu complex is predicted to be impermeant to the cell membrane, given the positive charges contributed by the copper ion, thus trapping the complex intracellularly and increasing the levels of ROS produced. This model makes two testable predictions. First, it predicts that TPEN is capable of stripping a significant proportion of copper away from cellular proteins. To determine whether this is the case, we measured the fraction of total cellular copper that is chelatable by TPEN under our experimental conditions. As shown in Figure 4F, $\sim 50 \%$ of the total cellular copper can be chelated by TPEN following incubation with $5 \mu \mathrm{M}$ TPEN for $24 \mathrm{hrs}$.

The second prediction from the proposed model is that cellular copper is essential for TPEN toxicity. Indeed if TPEN induces cell death through redox cycling after the formation of a TPEN-Cu complex, then reducing the enriched total cellular copper in cancerous HCT116 cells would be expected to reduce TPEN toxicity. To test whether this is the case we incubated HCT116 with the membrane permeant copper specific chelator neocuproine [31]. We chose neocuproine because of its specificity for copper and because the neocuproine- $\mathrm{Cu}$ complex in unlikely to be redox active [32]. Therefore, preincubation of HCT116 cells with neocuproine is expected to chelate cellular copper thus preventing TPEN from binding it. In the absence of the formation of TPEN-Cu complexes TPEN treatment should not produce ROS. Neocuproine by itself mildly reduces cellular viability (Figure 5A, Neo), probably due to the requirement for copper for normal cellular homeostasis. Importantly, incubating cells with neocuproine does not generate ROS (Figure 5B, Neo), showing that indeed the Neo-Cu complex is not redox active. However, pre-incubating HCT116 cells with neocuproine significantly reverses the toxic effect of TPEN (Figure 5A, Neo + TPEN), and this reduction in toxicity is coupled to a significant reduction in the levels of ROS generated (Figure 5B, Neo + TPEN5).

To test whether neocuproine reverses TPEN toxicity by chelating intracellular copper, we incubated cells with a membrane impermeant copper specific chelator, bathocuproine [33]. In contrast to neocuproine, bathocuproine did not reverse the cellular toxicity due to TPEN treatment (Figure 5C). Collectively these data show that TPEN toxicity requires cellular copper. When intracellular copper is chelated with neocuproine, a copper chelator that is effective at chelating copper but does not allow the TPEN-Cu complex to engage in redox reactions, TPEN becomes ineffective at producing ROS and killing colon cancer cells. Furthermore, as shown in Figure 2A with zinc, copper was also effective at reversing the toxic effects of TPEN and its ability to generate ROS in a dose dependent fashion (Figure 5A and B), showing that TPEN toxicity is dependent on its metal chelation properties.

\section{Tumoristatic activity of TPEN in vivo}

The ability of TPEN to selectively kill cancer cells raises the attractive possibility that it could have anti-tumor potential in vivo. To test whether this is the case we used a mouse xenograft colon cancer model. HCT116 colon cancer cells $\left(2-3 \times 10^{6}\right)$, were subcutaneously inoculated into the flank of NOD/SCID mice, and showed efficient engraftment as reflected by the development of malignant palpable tumor mass within 7-9 days post-inoculation. To investigate the therapeutic efficacy of TPEN, xenografted mice were injected intraperitoneally (i.p.) at 7 days postinoculation with TPEN $(20 \mathrm{mg} / \mathrm{kg})$ every other day for a 22 days therapy span. Tumor size was monitored in mice at different time points starting at day 7 post inoculation for both groups. In the TPEN treated group tumor volume was significantly reduced throughout the time course of tumor development with a volume of $11.6 \pm 0.37 \mathrm{~cm}^{3}$ in the control group versus $3.75 \pm 0.142 \mathrm{~cm}^{3}$ in the TPEN-treated group at day 22 (Figure 6A). In our hands TPEN was well tolerated at $15-20 \mathrm{mg} / \mathrm{kg}$, but not at $30 \mathrm{mg} / \mathrm{kg}$, consistent with previous reports [34].

Histological $\mathrm{H}$ \& $\mathrm{E}$ staining of tumor sections from untreated mice showed malignant cell infiltration and retention in the tissue (Figure 6B). However, TPEN-treated group showed a significant decrease of malignant cell nuclei staining relative to the control mice, consistent with the tumor growth profile (Figure 6A and B). In addition, the expression of $\mathrm{Ki}-67$, a nuclear protein proliferative marker, was reduced in TPEN-tissue section as depicted by immunostaining (Figure 6B). Furthermore, in vivo TPEN treatment induced apoptosis in tumor tissue as reported by TUNEL staining (Figure 6C). Collectively these data show that TPEN is effective at inhibiting the growth of colon cancer cells in vivo, arguing that metal chelation is a promising intervention for colon cancer treatment.

\section{Discussion}

Metals such as iron, copper and zinc are essential elements in mammalian cells and are used as cofactors or as structural components of many enzymes. However, an 
Figure $\mathbf{5}$ Cellular $\mathrm{Cu}$ is required for TPEN toxicity. A) Cellular viability using the MTT assay in cells that were either untreated (CON), incubated with $\mathrm{CuSO}_{4}(5 \mu \mathrm{M}, \mathrm{Cu})$; neocuproine $(25 \mu \mathrm{M}$, Neo); TPEN $(5 \mu \mathrm{M})$; pre-incubated with neocuproine $(25 \mu \mathrm{M})$ for $2 \mathrm{~h}$ before TPEN $(5 \mu \mathrm{M})$ addition (Neo + TPEN); pre-incubated with $\mathrm{CuSO}_{4}(5 \mu \mathrm{M})$ before TPEN (5 $\mu \mathrm{M}, \mathrm{Cu}+\mathrm{TPEN5})$ or TPEN (15 $\mu \mathrm{M}, \mathrm{Cu}+$ TPEN15) addition (mean $\pm \mathrm{SD}, \mathrm{n}=3$ ). B) ROS induction using the DCF assay in untreated cells (CON), cells incubated with $\mathrm{CuSO}_{4}(5 \mu \mathrm{M}$, Cu); neocuproine $(25 \mu \mathrm{M}$, $\mathrm{Neo}) ; \mathrm{H}_{2} \mathrm{O}_{2}(250 \mu \mathrm{M})$; TPEN $(5 \mu \mathrm{M})$; pre-incubated with neocuproine $(25 \mu \mathrm{M})$ for $2 \mathrm{~h}$ before TPEN $(5 \mu \mathrm{M})$ addition (Neo + TPEN); pre-incubated with $\mathrm{CuSO}_{4}(5 \mu \mathrm{M})$ before TPEN (5 $\mu \mathrm{M}, \mathrm{Cu}+$ TPEN5) or TPEN $(15 \mu \mathrm{M}$, $\mathrm{Cu}+\mathrm{TPEN15}$ ) addition (mean $\pm \mathrm{SD}, \mathrm{n}=3$ ). $\mathrm{C}$ ) MTT viability assay in untreated cells (CON); cells incubated with bathocuproine ( 5 and $10 \mu \mathrm{M})$ or TPEN $(5 \mu \mathrm{M})$, and in cells pre-incubated with bathocuproine

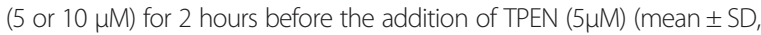
$n=3,{ }^{* *} p<0.01$, significant difference with respect to TPEN in $\mathbf{A}$ and $\mathbf{B}$ ).

excess of these metals causes toxicity. Therefore a balance between metal accumulation, their sequestration within cellular compartments, and their association with cellular proteins is essential for the maintenance of cell viability $[35,36]$. Transient intracellular elevations of free iron or copper is toxic because of their redox reactivity and participation in ROS metabolism. In particular, low molecular mass complexes of $\mathrm{Fe}^{\text {(II) }}$ and $\mathrm{Cu}{ }^{\text {(II) }}$ can react with hydrogen peroxide to generate hydroxyl radical, which is believed to be the most toxic form of ROS encountered in cells.

Here we show that this detrimental effect of transition metals can be used effectively to selectively eliminate cancer cells. TPEN is efficient at selectively eliminating colon cancer cells both in the dish and in vivo in mice. The mechanism of action of TPEN depends first on its high affinity for metals and as such its ability to strip intracellular metals from cellular proteins. Second colon cancer cells accumulate copper to significantly higher levels than normal colon cells. Finally, the TPEN-copper complex engages in redox cycling and the generation of ROS (hydroxyl radicals). Hence, TPEN selectively eliminates colon cancer cells using an elegant mechanism that relies on the biology of the cancer through its tendency to accumulate copper, a feature that is common to many other cancers including breast, ovarian, stomach, colorectal and leukemia [22]. As such the TPEN-dependent selective killing observed in this study is likely to be applicable to other cancers that accumulate redox active metals.

However, TPEN anti-tumor activity is likely to involve additional mechanisms since antioxidants treatment was not fully effective at reversing TPEN toxicity (Figure 3). TPEN toxicity is likely to be partly due to the removal of zinc from essential $\mathrm{Zn}$-dependent proteins as previously reported by others [7-15].

Another metal chelator that shows selective antitumor activity is di-2-pyridylk-etone-4,4,-dimethyl-3thiosemicarbazone (Dp44mT). Dp44mT is thought to 

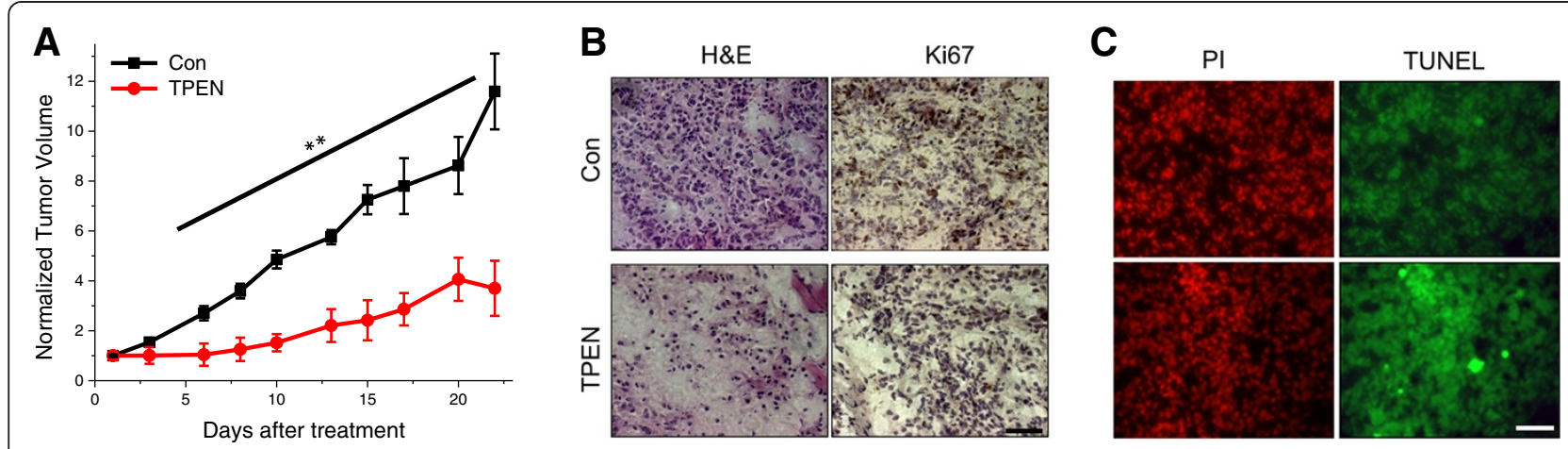

Figure 6 TPEN decreases the volume of colon cancer xenografts in mice. A) Graph showing a significant decrease in the volume of HCT116 colon cancer xenografts in mice injected with 20 mg/kg TPEN i.p., three times per week for 22 days. Tumor volumes were significantly smaller in TPEN-treated mice as compared to saline injected (Con) starting at day 6 after treatment (mean \pm SEM, $n=7-8,{ }^{* *} p<0.01$, significant difference with respect to Con in A). B) Histological ( $\mathrm{H} \& \mathrm{E}$ ) and immunohistochemical (Ki-67 antibody) staining in tumor xenografts. C) Apoptosis staining is revealed by using the TUNEL assay. Tissue was processed as described in "Methods." Identical fields are shown for propidium iodide (PI) stain of all nuclei (red fluorescence), and for fluorescein-labeled detection of TUNEL-positive nuclei (green fluorescence). Representative images were taken at 400X magnification. Scale Bar, $50 \mu \mathrm{m}$.

act in a similar fashion to TPEN through iron chelation and redox cycling to generate $\operatorname{ROS}[37,38]$. Dp44mT toxicity is also believed to involve activation of the lysosomal apoptotic pathway through its copper binding capacity [20].

Interestingly, cancer cells are known to have an altered redox status with an up-regulation of oxidative stress and an augmentation of antioxidant capacity (reviewed in [39]). It is also thought that a moderate increase in ROS enhances cell survival and proliferation [40]. Therefore the observed increase in ROS in cancer cells may promote tumorigenesis [39]. However, the increased basal ROS in cancer cells brings them closer to the toxicity threshold where the intrinsic antioxidant capacity, although enhanced, is not sufficient to contain toxic ROS levels [39]. Therefore increased oxidative stress in cancer cells represents an effective mechanism to eliminate cancer cells [39].

In summary, selective killing of colon cancer cells can be achieved using TPEN, where the transition metal-chelator complex engages in redox cycling and the generation of hydroxyl radicals. This is an attractive potential antitumor therapeutic approach because its mechanism of action depends on the biology of cancer cells, including the significant accumulation of copper and their endogenous enhanced oxidative stress. Therefore, selectivity toward elimination of cancer cells without affecting normal cells is inherent in this approach because of different homeostatic mechanisms in cancer versus normal cells. In that context it would be attractive to systematically explore the redox cycling potential of metal chelators already in the clinic for the treatment of other diseases.

\section{Conclusions}

TPEN, a membrane permeant metal chelator, selectively kills colon cancer cells without affecting the viability of normal cells. TPEN is effective at preventing tumor growth in a xenograft model. The mechanism of action of TPEN involves chelation of intracellular copper, making it available for redox cycling thus leading to the generation of ROS and cell death. Because colon cancer cells accumulate copper to 7 folds higher levels than control cells, this endows TPEN with its selective killing ability. Therefore, the mechanism of action of TPEN offers an attractive antitumor therapeutic approach potentially for a multitude of cancers that accumulate copper.

\section{Additional files}

Additional file 1: Figure S1. TPEN induces high ROS levels in

cancerous but not normal colon cells. Time course of TPEN-induced ROS generation in LoVo, SW480 and NCM460 cells. Control (Ctrl) represents cells that have been treated with DMSO carrier alone. ROS generated in response to $250 \mathrm{mM} \mathrm{H} 2 \mathrm{O} 2$ is also shown as a control (mean $\pm \mathrm{SD}, \mathrm{n}=3$ ). ** $p<0.01$, significant difference with respect to Ctrl.

Additional file 2: Figure S2. Antioxidants prevent TPEN-induced ROS generation in HCT116 cancer cells. Pretreatment with the antioxidants NAC or vitamin E decreased ROS production in cells treated with TPEN. ROS generated in response to $250 \mathrm{mM} \mathrm{H} 2 \mathrm{O} 2$ is also shown as a control (mean $\pm S D, n=3$ ). ${ }^{* *} p<0.01$, significant difference with respect to TPEN.

Additional file 3: Figure S3. Effect of TPEN on caspase activity. TPEN treatment (TPEN) significantly increased caspase-3 (A) and caspase-9 (B) above baseline (Ctrl). Pre-treatment with the antioxidant NAC decreases caspase-3 (A) and caspase-9 (B) activity below baseline levels at $12 \mathrm{~h}$.

\section{Abbreviations}

DCFDA: 2 ',7'-Dichlorofluorescin diacetate; DMSO: Dimethyl sulfoxide; Dp44mt: Di-2-pyridylketone-4,4-dimethyl-3-thiosemicarbazone; NAC: N-Acetylcysteine; Neo: Neocuproine; PARP: Poly aDP ribose polymerase; PBN: N-tert-butyl-alha-phenylnitrone; ROS: Reactive oxygen species; TPEN: $N, N, N^{\prime}, N^{\prime}$-tetrakis-[2-pyridylmethyl]-ethylenediamine; TUNEL: Terminal deoxynucleotidyl transferase dUTP nick end labeling; XIAP: X-Linked inhibitor of apoptosis.

Competing interests

The authors declare that they have no competing interests. 


\section{Authors' contributions}

MF, RAM, and DAS designed and performed experiments and analyzed data; $O R, A Z$, and $H H$ performed experiments; VEK, HGM and KM designed experiments and analyzed data; MF, HGM and KM wrote the paper. All authors read and approved the final manuscript.

\section{Acknowledgments}

This work was funded by NPRP grant \# 09-047-3-012 from the Qatar National Research Fund (QNRF). The statements made herein are solely the responsibility of the authors. Additional support for KM's Lab comes from the Biomedical Research Program at Weill Cornell Medical College in Qatar, a program funded by Qatar Foundation. We are grateful to Dr. Hussein Charif for his help with tissue immunostaining and to the members of the Kamal Shair Central Science Research Laboratory for their technical help.

\section{Author details}

${ }^{1}$ Department of Biology, American University of Beirut, Beirut, Lebanon. ${ }^{2}$ Department of Biology, Lebanese University, Beirut, Lebanon. ${ }^{3}$ Department of Environmental and Occupational Health, University of Pittsburgh,

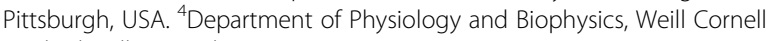
Medical College, Doha, Qatar.

Received: 21 October 2013 Accepted: 15 July 2014

Published: 21 July 2014

\section{References}

1. Vermeulen K, Van Bockstaele DR, Berneman ZN: The cell cycle: a review of regulation, deregulation and therapeutic targets in cancer. Cell Prolif 2003, 36:131-149.

2. Kastan MB, Bartek J: Cell-cycle checkpoints and cancer. Nature 2004, 432:316-323.

3. Sun L, Chai Y, Hannigan R, Bhogaraju VK, Machaca K: Zinc regulates the ability of Cdc25C to activate MPF/cdk1. J Cell Physio/ 2007, 213:98-104.

4. Arslan P, Di Virgilio F, Beltrame M, Tsien RY, Pozzan T: Cytosolic $\mathrm{Ca}^{2+}$ homeostasis in Ehrlich and Yoshida carcinomas. A new, membrane-permeant chelator of heavy metals reveals that these ascites tumor cell lines have normal cytosolic free $\mathrm{Ca}^{2+}$. J Biol Chem 1985, 260:2719-2727.

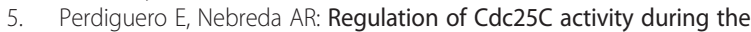
meiotic G2/M transition. Cell Cycle 2004, 3:733-737.

6. Kim AM, Vogt S, O'Halloran TV, Woodruff TK: Zinc availability regulates exit from meiosis in maturing mammalian oocytes. Nat Chem Biol 2010, 6:674-681

7. Zalewski PD, Forbes IJ, Betts WH: Correlation of apoptosis with change in intracellular labile Zn (II) using zinquin [(2-methyl-8-ptoluenesulphonamido-6-quinolyloxy) acetic acid], a new specific fluorescent probe for Zn (II). Biochem J 1993, 296(Pt 2):403-408.

8. Kolenko VM, Uzzo RG, Dulin N, Hauzman E, Bukowski R, Finke JH: Mechanism of apoptosis induced by zinc deficiency in peripheral blood T lymphocytes. Apoptosis 2001, 6:419-429.

9. Chai F, Truong-Tran AQ, Evdokiou A, Young GP, Zalewski PD: Intracellular zinc depletion induces caspase activation and p21 Waf1/Cip1 cleavage in human epithelial cell lines. J Infect Dis 2000, 182:S85-S92.

10. Nakatani T, Tawaramoto M, Opare KD, Kojima A, Matsui-Yuasa I: Apoptosis induced by chelation of intracellular zinc is associated with depletion of cellular reduced glutathione level in rat hepatocytes. Chem Biol Interact 2000, 125:151-163.

11. Hashemi M, Ghavami S, Eshraghi M, Booy EP, Los M: Cytotoxic effects of intra and extracellular zinc chelation on human breast cancer cells. Eur J Pharmacol 2007, 557:9-19.

12. Gurusamy KS, Farooqui N, Loizidou M, Dijk S, Taanman JW, Whiting S, Farquharson MJ, Fuller BJ, Da BR: Influence of zinc and zinc chelator on HT-29 colorectal cell line. Biometals 2011, 24:143-151.

13. Ding $W Q, Y u H J$, Lind SE: Zinc-binding compounds induce cancer cell death via distinct modes of action. Cancer Lett 2008, 271:251-259.

14. Donadelli M, Dalla Pozza E, Costanzo C, Scupoli MT, Scarpa A, Palmieri M: Zinc depletion efficiently inhibits pancreatic cancer cell growth by increasing the ratio of antiproliferative/proliferative genes. J Cell Biochem 2008, 104:202-212

15. Makhov P, Golovine K, Uzzo RG, Rothman J, Crispen PL, Shaw T, Scoll BJ, Kolenko VM: Zinc chelation induces rapid depletion of the X-linked inhibitor of apoptosis and sensitizes prostate cancer cells to TRAIL-mediated apoptosis. Cell Death Differ 2008, 15:1745-1751.

16. Ding $X$, Xie $H$, Kang $Y J$ : The signifcance of copper chelators in clinical and experimental application. J Nutr Biochem 2011, 22:301-310.

17. Armstrong C, Leong W, Lees GJ: Comparative effects of metal chelating agents on the neuronal cytotoxicity induced by copper $(\mathrm{Cu}+2)$, iron $(\mathrm{Fe}+3)$ and zinc in the hippocampus. Brain Res 2001, 892:51-62.

18. Dilda PJ, Hogg PJ: Arsenical-based cancer drugs. Cancer Treat Rev 2007, 33:542-564.

19. Jungwirth U, Kowol CR, Keppler BK, Hartinger CG, Berger W, Heffeter P: Anticancer activity of metal complexes: involvement of redox processes. Antioxid Redox Signal 2011, 15:1085-1127.

20. Lovejoy DB, Jansson PJ, Brunk UT, Wong J, Ponka P, Richardson DR: Antitumor activity of metal-chelating compound Dp44mT is mediated by formation of a redox-active copper complex that accumulates in lysosomes. Cancer Res 2011, 71:5871-5880.

21. Trinder D, Zak O, Aisen P: Transferrin receptor-independent uptake of differic transferrin by human hepatoma cells with antisense inhibition of receptor expression. Hepatology 1996, 23:1512-1520.

22. Gupte A, Mumper RJ: Elevated copper and oxidative stress in cancer cells as a target for cancer treatment. Cancer Treat Rev 2009, 35:32-46.

23. Gali-Muhtasib H, Kuester D, Mawrin C, Bajbouj K, Diestel A, Ocker M, Habold C, Foltzer-Jourdainne C, Schoenfeld P, Peters B, Diab-Assaf M, Pommrich U, Itani W, Lippert H, Roessner A, Schneider-Stock R: Thymoquinone triggers inactivation of the stress response pathway sensor CHEK1 and contributes to apoptosis in colorectal cancer cells. Cancer Res 2008, 68:5609-5618.

24. Hornle M, Peters N, Thayaparasingham B, Vorsmann H, Kashkar H, Kulms D: Caspase-3 cleaves XIAP in a positive feedback loop to sensitize melanoma cells to TRAIL-induced apoptosis. Oncogene 2011, 30:575-587.

25. Carraway RE, Dobner PR: Zinc pyrithione induces ERK- and PKC-dependent necrosis distinct from TPEN-induced apoptosis in prostate cancer cells. Biochim Biophys Acta 1823, 2012:544-557.

26. Hyun HJ, Sohn JH, Ha DW, Ahn YH, Koh JY, Yoon YH: Depletion of intracellular zinc and copper with TPEN results in apoptosis of cultured human retinal pigment epithelial cells. Invest Ophthalmol Vis Sci 2001, 42:460-465.

27. Adler M, Shafer H, Hamilton T, Petrali JP: Cytotoxic actions of the heavy metal chelator TPEN on NG108-15 neuroblastoma-glioma cells. Neurotoxicology 1999, 20:571-582.

28. Gunay A, Theopold $\mathrm{KH}$ : C-H bond activations by metal oxo compounds. Chem Rev 2010, 110:1060-1081.

29. Nam W: High-valent iron (IV)-oxo complexes of heme and non-heme ligands in oxygenation reactions. Acc Chem Res 2007, 40:522-531.

30. Lyakin OY, Bryliakov KP, Talsi EP: EPR, $1 \mathrm{H}$ and $2 \mathrm{H}$ NMR, and reactivity studies of the iron-oxygen intermediates in bioinspired catalyst systems. Inorg Chem 2011, 50:5526-5538.

31. Mohindru A, Fisher JM, Rabinovitz M: 2,9-Dimethyl-1,10-phenanthroline (neocuproine): a potent, copper-dependent cytotoxin with anti-tumor activity. Biochem Pharmacol 1983, 32(23):3627-3632.

32. Zubair H, Khan HY, Sohail A, Azim S, Ullah MF, Ahmad A, Sarkar FH, Hadi SM: Redox cycling of endogenous copper by thymoquinone leads to ROS-mediated DNA breakage and consequent cell death: putative anticancer mechanism of antioxidants. Cell Death Dis 2013, 4:e660.

33. Peters ZJ, Nykamp JA, Passaperuma K, Carlson JC, DeWitte-Orr SJ, Greenberg BM, Bols NC: Effect of copper on the cytotoxicity of phenanthrene and 9,10-phenanthrenequinone to the human placental cell line, JEG-3. Reprod Toxicol 2007, 23:520.

34. Adler M, Dinterman RE, Wannemacher RW: Protection by the heavy metal chelator N, N, N', N'-tetrakis (2-pyridylmethyl) ethylenediamine (TPEN) against the lethal action of botulinum neurotoxin A and B. Toxicon 1997, 35:1089-1100

35. Finney LA, O'Halloran TV: Transition metal speciation in the cell: insights from the chemistry of metal ion receptors. Science 2003, 300:931-936.

36. Beyersmann $D$, Haase $H$ : Functions of zinc in signaling, proliferation and differentiation of mammalian cells. Biometals 2001, 14((3-4)):331-341.

37. Richardson DR, Sharpe PC, Lovejoy DB, Senaratne D, Kalinowski DS, Islam M, Bernhardt PV: Dipyridyl thiosemicarbazone chelators with potent and selective antitumor activity form iron complexes with redox activity. J Med Chem 2006, 49:6510-6521.

38. Whitnall M, Howard J, Ponka P, Richardson DR: A class of iron chelators with a wide spectrum of potent antitumor activity that overcomes 
resistance to chemotherapeutics. Proc Natl Acad Sci U S A 2006, 103:14901-14906.

39. Trachootham D, Alexandre J, Huang P: Targeting cancer cells by ROSmediated mechanisms: a radical therapeutic approach? Nat Rev Drug Discov 2009, 8:579-591.

40. Boonstra J, Post JA: Molecular events associated with reactive oxygen species and cell cycle progression in mammalian cells. Gene 2004, 337:1-13.

doi:10.1186/1471-2407-14-527

Cite this article as: Fatfat et al:: Copper chelation selectively kills colon cancer cells through redox cycling and generation of reactive oxygen species. BMC Cancer 2014 14:527.

\section{Submit your next manuscript to BioMed Central and take full advantage of:}

- Convenient online submission

- Thorough peer review

- No space constraints or color figure charges

- Immediate publication on acceptance

- Inclusion in PubMed, CAS, Scopus and Google Scholar

- Research which is freely available for redistribution 